\title{
Questão agrária \\ e macropolíticas para a Amazônia
}

FRANCISCO DE ASSIS COSTA

\section{Introdução}

$\mathrm{N}$

A terceira semana de maio de 2003, o Ministério do Planejamento, Orçamento e Gestão lançou o documento "Plano Plurianual 2004-2007 Orientação Estratégica de Governo 'Um Brasil para Todos': Crescimento sustentável, emprego e inclusão social” (PPA-OE), com o objetivo de

$[\ldots]$ inaugurar a seguinte estratégia de longo prazo: inclusão social e desconcentração da renda com crescimento do produto e do emprego. Crescimento ambientalmente sustentável, redutor das desigualdades regionais. Dinamizado pelo mercado de consumo de massa, por investimento e pela elevação da produtividade. E redução da vulnerabilidade externa através da expansão de atividades competitivas que viabilizem esse crescimento sustentado. (PPA-OE, I.9).

Trata-se de documento atual, no qual se explicitam, mais claramente que em enunciados posteriores, disposições estratégicas que vigem no novo governo ${ }^{1}$. Ao lado da reafirmação da necessidade de desenvolvimento com base na expansão do mercado interno, em particular o que deriva do consumo de massa - o modelo que, em suas linhas gerais, vem orientando discussões internas e atuações políticas do PT há muito tempo - colocam-se duas novidades de grande significado, a saber: a elevação da estabilidade macroeconômica à condição de pressuposto e da sustentabilidade ambiental à condição de atributo do desenvolvimento.

Esses dois adendos resultam da incorporação política de uma percepção mais complexa e realista da sociedade brasileira. Assim, tornam visíveis, exigindo tratamento, problemas antes obscurecidos, que se somam às já conhecidas dificuldades do desenvolvimento brasileiro: aos amplamente discutidos impasses impostos à acumulação dinâmica - ao crescimento econômico sustentado - pela segmentação de mercados resultante da concentração da renda, acrescem-se agora aqueles derivados da necessidade de conciliar, por uma parte, soluções da economia real para problemas nacionais com as exigências da economia monetária global e, por outra, soluções econômicas com sustentabilidade ambiental.

Esses novos desafios não são triviais, podendo mesmo configurar dilemas de grande envergadura. Eles significam, a rigor, que as soluções econômicas para, por exemplo, desconcentrar renda (objetivo primordial), terão que ser conciliadas, em nome da governabilidade, com os parâmetros do mercado financeiro; em nome da coerência estratégica de um projeto político transformador, com os parâmetros de sustentabilidade ecológica. 
A questão amazônica situa-se numa interseção particular do conjunto de possibilidades econômicas que o País dispõe, com o conjunto de seus problemas associados à concentração da renda e com, ainda, o conjunto de seus problemas ambientais. Não se trata, todavia, de mera superposição - trata-se de tecido produzido por relações sociais próprias que, forjadas na interação com uma natureza originária de peculiaridade já largamente realçada, não são redutíveis de modo abstrato e homofórmico às condições e necessidades vigentes no restante do País. De modo que a equação que se pretende resolver para a superação dos desafios que o Governo se coloca pensando o País como um todo, podem apresentar inconsistências com os seus próprios termos na Amazônia. A reflexão que faço a seguir procura descortinar tais inconsistências e indicar as possibilidades de sua superação.

\section{As múltiplas faces da realidade amazônica e os macrodesafios do poder federal na Amazônia}

A Amazônia tem sido foco da atenção mundial como natureza e como sociedade (Costa, 2003). Na primeira condição destaca-se a importância da maior floresta tropical do planeta como acervo de biodiversidade e como base de prestação de serviços ambientais para a estabilização do clima global. Na segunda, ressaltam-se os usos da base natural da região que se fazem (a não ser em poucas exceções sempre lembradas) pondo em risco tudo o que se poderá obter de uma utilização mais qualificada - nas expressões correntes, racionais - das suas características naturais e dos seus atributos locacionais. A conclusão é de que a dimensão social da região, incluindo as intervenções políticas, constitui um paradoxo por realizar-se destruindo, em nome dos ganhos presentes de poucos, os mais preciosos trunfos para um futuro melhor para todos.

Há realismo e equívocos nessa proposição, cuja consideração é imprescindível à discussão sobre uma nova forma de atuação governamental na região.

São reais os riscos ambientais de muitas das práticas econômicas que se detectam na região, ao par de prejuízos inquestionáveis ou benefícios sociais discutíveis. Mas é falso considerar irracionais os processos decisórios privados que fundamentam tais usos, ou sem sentido os cálculos de custo-benefício que nesse nível se processam. O justo é expor os dilemas aí vivenciados, para tratá-los institucionalmente: mediante necessidades presentes que só conseguem ser atendidas por usos tradicionais (insustentáveis) da base natural, usos modernos (sustentáveis) que se apresentam como promessa de atendimento de necessidades futuras serão sempre postergados. É função do Estado, na Amazônia, e certamente um macrodesafio do poder federal na Amazônia, atuar no sentido de anular o hiato de tempo existente entre formas modernas e sustentáveis de uso dos recursos naturais da região e as necessidades cotidianas de suas populações.

É pertinente, por outra parte, a percepção de que muitas das intervenções estatais se fizeram na região corroborando práticas ambientalmente deletérias, ao lado de aprofundarem mazelas sociais, excluindo os mais necessitados e confirmando o poder econômico e político dos mais fortes. É justo, ainda, argu- 
mentar que tais ações resultaram de um certo conteúdo patrimonialista que tem marcado, com raízes profundas, o estado brasileiro, vinculado-o a privilégios de segmentos sociais específicos. Mas não é certo presumi-lo cristalizado nessa condição. É possível e necessário tornar o Estado na Amazônia permeável à pluralidade de forças que expressam a diversidade social e cultural da região, dotando-o de mecanismos que o façam eficiente como indutor de desenvolvimento pela correção das desigualdades econômico-sociais. É certamente um outro macrodesafio do poder federal na Amazônia ser peça vital dessa transformação.

É certo que atores privados, com o suporte de instituições do Estado, têm historicamente aportado a região com matrizes tecnológicas inadequadas pois, como a mentalidade de seus operadores, foram forjadas na relação com outros ecossistemas. Tais matrizes desenvolveram-se pelo esforço da ciência em criar sistemas botânicos homogêneos para maximizar a produção de biomassa por uma lógica de industrialização da agricultura fortemente assentada em bases mecânico-químicas. As técnicas daí derivadas, por serem aparatos de padronização, negam o capital natural contido na diversidade biológica. Por seu turno, as mesmas características ecológicas da região que explicam sua gigantesca biodiversidade negam essas matrizes, reduzindo dramaticamente os ciclos de vida e a economicidade de suas técnicas. Um terceiro macrodesafio do poder federal na Amazônia é, pois, o de orientar alterações nas pautas das instituições de Ciência \& Tecnologia na região para que, atuando orientadas pelo princípio da diversidade em substituição ao da padronização e da homogeneidade, possam produzir técnicas ajustadas às necessidades regionais.

\section{Riscos ambientais e racionalidades econômicas}

Há dois, chamemos assim, projetos de desenvolvimento de base rural em andamento na Amazônia, cujos protagonistas nas suas interações conflitivas ou cooperativas, nos seus antagonismos e contradições configuram a questão agrária na região. Eles diferenciam-se nas formas de tratamento do capital natural (cuja referência primordial é o bioma da floresta amazônica), na intensidade do uso de capital humano e social e nas proporções de uso de capital físico e trabalho.

Um que se caracteriza por uma absorção do capital natural a que acessa de modo que a mata $=$ madeira (extrativismo de aniquilamento) e o solo $=$ suporte de agropecuária homogênea, para produção de gado ou grãos (comodities); nesse modelo, o trabalho direto = trabalho assalariado desqualificado e a elevação da produtividade não depende da qualificação do trabalho; a relação de propriedade = latifundiária (propriedades de grande extensão); a relação capital físico (dominantemente na forma de kits mecânico-químicos)/ trabalho = alta; a relação capital humano/ trabalho = baixa; a relação terra / trabalho = alta; a relação capital físico / terra = baixa; a relação capital físico / trabalho = alta; o trabalho de gestão = empresarial (orientada ao lucro).

Um outro projeto em andamento caracteriza-se pelos seguintes atributos: o capital natural é absorvido de modo que a mata = extenso conjunto de produ- 
tos obtidos por extrativismo de coleta e o solo = suporte de agropecuária diversa; o trabalho direto $=$ familiar, onde a elevação da produtividade depende da qualificação do trabalhador direto; relação de propriedade = propriedades de pequena extensão; relação capital (humano, na forma de saber difuso, ancestral e/ ou recente) $/$ trabalho = alta; relação terra $/$ trabalho = baixa; relação capital (humano) / terra = alta; relação capital físico / trabalho = baixa; relação capital físico/ terra $=$ alta; $\mathrm{o}$ trabalho de gestão $=$ familiar, orientada à eficiência reprodutiva .

O primeiro projeto constitui a forma de evolução de uma unidade estrutural: a formada pela conjunção entre propriedade latifundiária, trabalho assalariado e produção homogênea de gado e grãos, a qual chamaremos de latifundiária-monocultural. Os riscos ambientais a ele associados são consideráveis porque a realização de sua finalidade (o lucro) pressupõe uma padronização elevada das bases produtivas, podendo implicar cisão profunda entre elementos chave do processo de reprodução equilibrada dos circuitos vitais da natureza. E, quando se fortalece essa estrutura, quando maximiza seus objetivos, a tensão tende a se elevar: porque mais extensa e intensamente ela transforma os fundamentos naturais. Paralelamente, tanto no caso do gado, quanto no caso dos grãos, no primeiro pelo extenso uso da terra, no segundo pela utilização intensa de capital mecânico e químico, sua capacidade de agregar renda diretamente e de criar tensões para a formação de capital humano, por qualificação do trabalhador, ou capital social, por indução à sua organização, é tendencialmente baixa. No ambiente rural, tem se demonstrado concentrador de meios de produção e renda.

O segundo projeto é a forma de evolução da unidade estrutural pequena propriedade familiar-produção diversificada, a qual chamaremos aqui familiarpolicultural. Os riscos ambientais associados à maioria de suas formas são relativamente baixos, sobretudo porque atua por uma racionalidade reprodutiva para a qual ser eficiente, atender eficientemente à sua finalidade significa duas coisas: limitar a expansão ao limites da capacidade de trabalho da família e elevar a qualidade de vida com máxima segurança para a unidade familiar. A escala é, assim, reduzida, e a diversidade é alta, constituindo, em muita situações, a diversidade em si, uma força produtiva, uma qualidade econômica, uma capacidade dos sistemas produtivos aí desenvolvidos. Não há inovação, aqui, sem compartilhamento difuso do saber a ela associado. Por outra parte, dificilmente se dá consistência às formas concretas desse projeto sem algum tipo de associativismo. A formação de capital humano e social é conseqüência quase mecânica, direta, do seu fortalecimento. Assim como a elevação da eqüidade social, posto que, baseada em acesso desconcentrado dos meios de produção, seu fortalecimento é, de modo direto, distribuição de renda.

Esses projetos têm um elevadíssimo grau de antagonismo, dado que competem pelos mesmos recursos físicos (para absorvê-los em formas distintas e excludentes, como se viu), humanos (trabalho) e sociais (infra-estruturais e institucionais). A dimensão mais visível desse antagonismo é a representada pe- 
los conflitos fundiários. Mas há um campo de disputa no plano institucional2, não tão claramente percebido, em torno de políticas públicas e recursos sociais de toda ordem. A política dos incentivos fiscais gerida pela Superintendência de Desenvolvimento da Amazônia - Sudam marcou um período de completa hegemonia da unidade estrutural latifúndio-monocultura. A mais recente e ilustrativa peleja trava-se em torno dos recursos do Fundo Constitucional de Desenvolvimento do Norte - FNO. A observação desse embate é central para indicar tendências e possibilidades.

\section{Intervenção estatal, antagonismos sociais e riscos ecológicos}

A Sudam caracterizou uma atuação do poder federal na Amazônia, sobretudo na sua parte oriental, marcada pela valorização do projeto latifundiáriomonocultura, em dois períodos. Um que se fez totalmente atrelado a determinações verticais, onde relações hierarquizadas a partir das regiões mais desenvolvidas do País definiram os atores privilegiados e suas formas de aportar a região. A essa estratégia, que durou todo o período da ditadura militar até sua crise terminal no início dos anos de 1980, chamei em outro lugar de brasilianização da Amazônia (Costa, 1992). Um outro período, cujos traços se definem em meados dos anos de 1980 e se prolonga até o fim da Sudam, em 2001, caracterizarse-á pelo que chamei de reoligarquização do agrário da região (Costa, 2000). A designação procura realçar o fato de que o acesso aos recursos federais agora se tornou facilitado para segmentos das elites locais, a partir de relações horizontais socialmente enviesadas e politicamente funcionalizadas por forças ancoradas em bases tradicionais de poder, em que a estrutura hierárquica culmina em algum chefe local, encastelados, por razões históricas diversas, no Partido da Mobilização Democrática Brasileira. Em ambos os momentos a atuação federal é marcada por uma "[...] burocracia estatal [que] ao mesmo tempo em que fortalece seu núcleo de poder, insulando-se no interior da estrutura estatal, negocia as demandas de forma patrimonial. Esse sistema redunda na utilização privada daquilo que seria público" (Brito, 2001, p. 230).

O processo de redemocratização do País e a penetração nos debates subjacentes de uma crítica ecológica dos processos de incorporação econômica da região colocaram na agenda política, pela primeira vez, a seguinte questão: como conciliar desenvolvimento socialmente justo com esperança de sustentabilidade ecológica elevada, na região amazônica?

Tal indagação é também suscitada pelas indicações estratégicas atuais de governo - é parte da problematização que vem orientando sua abordagem quanto ao desenvolvimento regional. Convém enfatizar, todavia, que emergiu e teve tratamento já no processo constituinte da transição democrática. A Constituição de 1988 e os trâmites derivados de sua regulamentação encaminharam a ela uma resposta: produzir-se-á tal desenvolvimento na Amazônia alocando recursos sociais provindos das regiões mais ricas para o fortalecimento do processo evolutivo da unidade estrutural familiar-policultural na região. Não é senão isto, com 
efeito, o que estabelece a Lei n $\mathrm{o}$ 7.827, de setembro de 1989, que regulamenta o artigo 159, I, c, da Constituição Federal que determinou que 3\% das receitas da União deveriam ser aplicados em programas de financiamento de setores produtivos das regiões consideradas as menos favorecidas do País. Além de estabelecer as proporções de distribuição do Fundo entre as três regiões contempladas $0,6 \%$ para o Norte, $0,6 \%$ para o Centro-oeste e $1,8 \%$ para o Nordeste - o mencionado estatuto estabelece, textualmente, que os recursos devem dar preferência aos mini e pequenos produtores para implementação de sistemas produtivos ecologicamente adequados ${ }^{3}$.

Tratava-se de inversão profunda na orientação da política de desenvolvimento regional de base agrária: no lugar da pecuária de corte, culturas perenes; no lugar das grandes empresas e fazendas, as unidades familiares de produção; no lugar de sistemas homogêneos, sistemas diversos. Uma disposição em substituir o projeto latifundiário-monocultural pelo familiar-policultural, o qual, ademais de apontar para um desenvolvimento com raízes mais profundas, indicaria a possibilidade de tê-lo ecologicamente prudente e com capacidade de formação e distribuição de renda ${ }^{4}$.

\section{Ambigüidades e oportunismo na prática do FNO}

A prática do FNO produziu a grande mudança? Os arranjos que se fizeram em torno do Fundo implementaram a preferência pelos produtores familiares (pensados nas categorias de mini e pequenos produtores rurais, pelo texto legal) e pelos sistemas produtivos ecologicamente adequados à Região, como preconizava a Lei n ${ }^{\circ} 7.827$ de 1989 ?

A resposta a esta questão exige perspectiva histórica e esforço analítico. As séries relativas à aplicação do FNO mostram o seguinte (ver Gráficos l e 2 e suas notas metodológicas):

1. De 1990 a 1995, as aplicações fizeram-se dominantemente para a pecuária (oscilações em torno do patamar de $80 \%$, com ligeira tendência de queda). De modo corresponddente a isso, verifica-se uma situação de total domínio por beneficiários patronais nos três primeiros anos do período (em torno de $80 \%$ ), para um situação paritária nos dois últimos anos.

2. De 1995 a 1998, a participação relativa dos financiamentos para culturas permanentes, que com oscilações variara de $10 \%$ para $20 \%$ nos cinco anos anteriores, chega a $60 \%$, produzindo uma redução correspondente na participação da pecuária. Nesse período, a participação da produção familiar cresceu significativamente, chegando, no ponto alto da série, a atingir os $80 \%$.

3. De 1998 a 2000, cai rapidamente a participação das permanentes para aproximadamente $30 \%$. No mesmo período, a proporção da produção familiar cai acentuadamente, sendo novamente superada pelos produtores patronais no ano de 2000 .

Em suma, a realidade do FNO não tem sido a da afirmação veemente de nova base de desenvolvimento. No primeiro período prevalece o "velho" proje- 
to latifundiário-monocultural; no segundo período, teve primazia nítida o projeto familiar-policultural e, no terceiro período, tende a retomar força o projeto latifundiário-monocultural. Há, pois, no exercício das relações concertadas pelo FNO, uma tensão clara entre um modelo e o outro, vencendo, na maior parte do tempo, o primeiro deles: precisamente aquele cuja interpelação, por delegação constitucional, deveria ser a razão de ser do FNO.

Gráfico l - Evolução da participação dos financiamentos do FNO para pecuária e para culturas permanentes ${ }^{1}, 1990$ a 2000

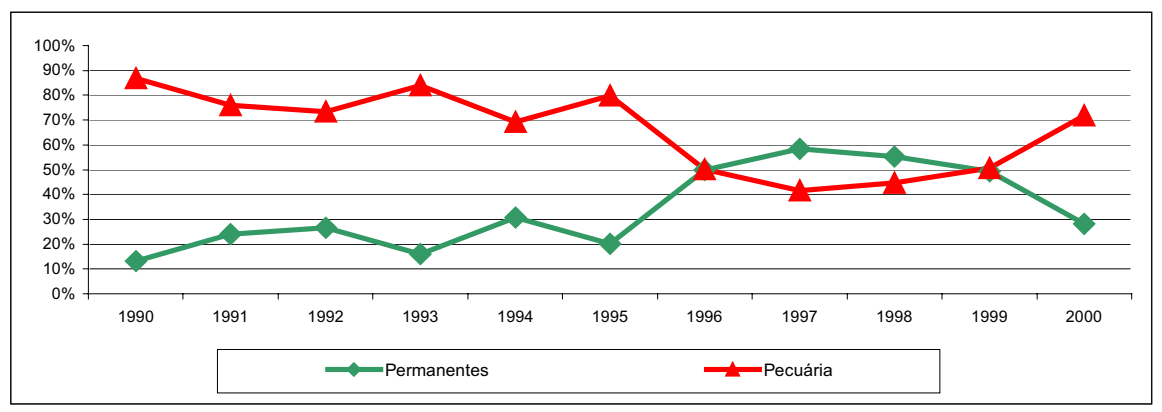

Gráfico 2 - Evolução da participação dos financiamentos do FNO por porte/tipo do beneficiário ${ }^{2}, 1990$ a 2000

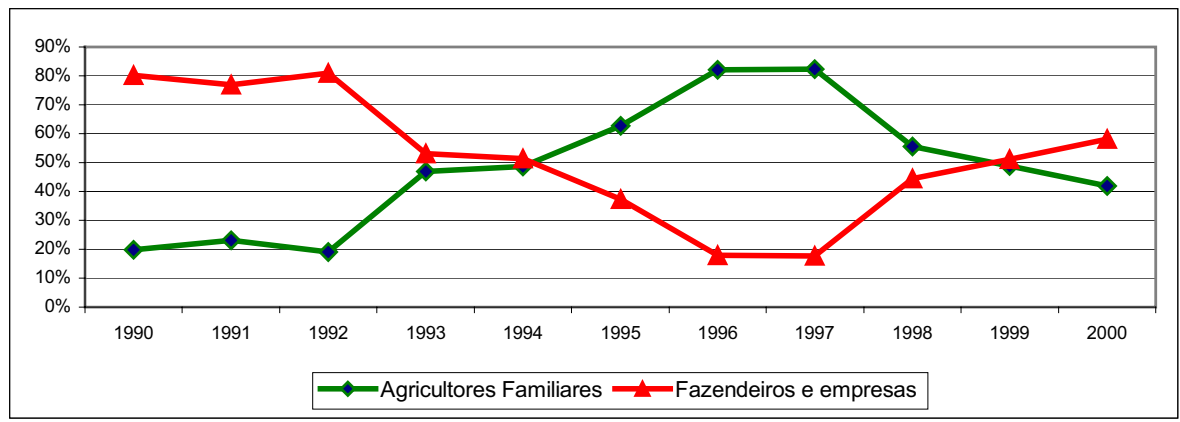

Gráfico 3 - Evolução dos repasses anuais, dos contratos de crédito e do disponível ${ }^{3}$, em comparação com a evolução do valor percentual dos créditos contratados em relação ao disponível (taxa de eficiência bancária) do FNO, 1990 a 2000

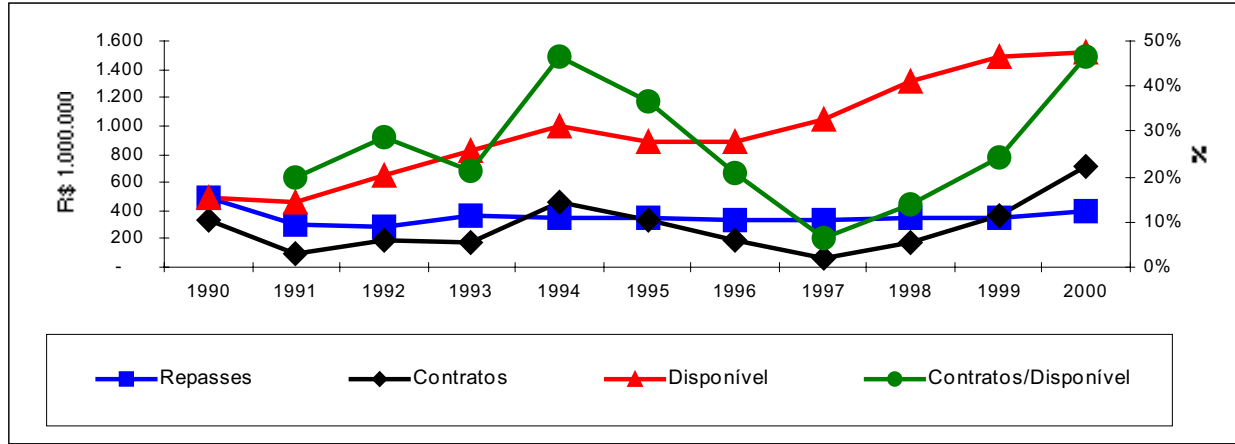

Fonte: Secretaria do Tesouro Nacional, Relatórios do Basa, Basa/ Derur-Dicop e Santana, 2000. 
Notas metodológicas dos Gráficos 1 a 3

1. As percentagens consideram a soma dos créditos para culturas permanentes e para pecuária como $100 \%$. Considera-se, para isso, que todos os demais itens de crédito para o setor rural distribuem-se proporcionalmente a essas duas parcelas, isto é, que as culturas temporárias financiadas foram intercalares para cultura permanente ou pasto; que os investimentos em infra-estrutura e que as aplicações tecnológicas serviram às permanentes ou à pecuária proporcionalmente aos pesos dos créditos respectivos.

2. Houve variação nos critérios que definiram as categorias de usuários do FNO, ao longo do período, numa flexibilidade tal que borrou as fronteiras das categorias de mini e pequenos produtores, comumente associadas à produção familiar. Os critérios de enquadramento variaram para os mini produtores (até cinco módulos rurais e Valor Bruto da Produção, VBP, muito alto entre 1989 e 1991; até dois módulos rurais e VBP reduzido, de 1992 a 1994, cf. Tura, 2000, p. 39) e, mais significativamente, para os pequenos produtores. A média dos valores emprestados variou, por isso, fortemente. Quanto aos miniprodutores, verificaram-se maiores valores no início do período, crescendo de R\$17.345 em 1989 para R 24.712 em 1990, chegando a R\$ 36.539 em 1991. Entre 1992 e 1998, situou-se abaixo do R\$10.000, com os valores mínimos nos dois primeiros anos ( R\$ 4.684 e R\$ 4.243) e o máximo de R\$ 9.770 em 1995. A média dos contratos dos pequenos produtores variou também fortemente, sendo R\$ 160.898 por contrato em 1989, R\$ 90.211 em 1991, situando-se em torno dos R\$ 56.000 nos dois próximos anos; entre 1995 e 1997 atinge seus valores mais baixos, em torno de $\mathrm{R} \$ 40.000$. Volta a crescer fortemente em 1998, para R\$178.398, atingindo em 2000 R\$ 77.528. Face a isso, entendeu-se que não foram em todos os anos que a categoria de pequenos produtores utilizada pelo Basa poderia ser considerada como parte do universo da produção familiar. Considerou-se, assim, que este seria o caso apenas quando a média dos contratos fosse inferior a R 50.000 - quando superasse esse valor a clientela em questão extrapolava o conjunto dos que poderiam ser tratados como produtores familiares, agregando-se mais adequadamente aos produtores patronais (fazendas e empresas).

3. Saldo de um ano t-1, mais repasses do ano $t$, menos contratos de crédito no ano $t$. As disponibilidades aqui não consideram, portanto, os retornos de empréstimos passados. Os valores estão em Reais de 2001.

A taxa de eficiência bancária expressa essa tensão na medida em que aumenta quando o modelo a superar prevalece e reduz quando, ao contrário, é o novo modelo que assume a proeminência (cf. Gráfico 3). Ela indica, assim, existirem, atuando sobre o FNO, forças que confirmam o que deveria ser negado e negam o que deveria ser confirmado na perspectiva de um novo estilo de desenvolvimento para a região. Elucidar as forças que produzem um tal paradoxo é fundamental para discutir novas formas de intervenção federal.

Há duas análises para a história indicada pelos dados acima. Uma interpretação parte da tecnocracia do Basa, outra das lideranças camponesas. Na primeira, elementos de uma tecnocracia que se entende ciente das necessidades regionais e solidária com os mais humildes, esclarecem sua adesão imediata ao novo 
tipo de desenvolvimento preconizado na Lei n 07.827 e sua satisfação em dispor de instrumentos para contra-arrestar o modelo depredador e excludente com o qual foi obrigado a pactuar, como coadjuvante, no reinado da Sudam ${ }^{5}$. Aduz, todavia, ser a mudança portadora de enormes riscos, com os quais teve (tem) que lidar profissionalmente, maduramente. A preparação das novas regras exigiu cuidados que demandaram longo tempo de estudos para a adequação dos contratos aos novos clientes e aos novos produtos e para garantir as salvaguardas das instituições de pesquisa e extensão, indubitavelmente habilitadas a garantir a eficiência dos sistemas produtivos que garantiriam um novo desenvolvimento. Enquanto isso, prevaleceram circunstancialmente as velhas regras, confirmadoras do projeto latifundiário-monocultural. Isso explicaria a primeira fase - $1990 \mathrm{a}$ 1995. A segunda fase seria o momento da mudança, no qual ao projeto familiarpolicultural, mediante contratos justos - com cláusulas duras, porém obviamente necessárias -, acordados em longas rodadas de negociação, viria a ser dada prioridade total. Dois fatores, contudo, frearam esse ímpeto: a) o novo cliente mostrou-se limitado na sua capacidade de absorção de crédito e b) os novos produtos apresentaram maior potencial de risco que o previsto. A produção familiar rural teria se mostrado inábil para a tarefa, garantem, dado seu tradicionalismo (conservadorismo, apego ao passado) e insuficiente disponibilidade em capital humano e social. Ao mesmo tempo, desenvolveram-se argumentos que alargaram, às suas vistas, as possibilidades do desenvolvimento sustentável: não seria condizente com esse novo tipo de desenvolvimento a reforma de pastagens, dado que se poderia imaginar que isso contenha o avanço sobre a floresta? Não seria condizente com esse novo tipo de desenvolvimento o financiamento de uma pecuária baseada em animais de alto rendimento, dado que isso colocaria possibilidades de maior confinamento dos rebanhos e, ipso facto, menor tensão sobre a floresta? Não podem ser tratados como promotores de sustentabilidade os que estão dispostos a reformar pastagens e adquirir embriões de um gado hightech? Nessa perspectiva, os limites dos camponeses como base de um processo de desenvolvimento e a requalificação da pecuária explicariam a passagem da segunda para a terceira fase.

Todo o thriller, na narrativa, poderia ser assim resumido: o principal instrumento (oferecido pela Lei $\mathrm{n}^{\mathrm{o}}$ 7.827) de ação estratégica do Estado nacional para o desenvolvimento sustentável na região Amazônica teria uma incorreção de fundo: aquele ator indicado como preferencial no processo não teria capacidade para tanto. Restaria à tecnocracia gestora dos mecanismos de política federal lamentar o oportunismo ${ }^{6}$ de tal sujeito social em acatar como verdadeira uma presunção populista, como tantas outras da "constituição cidadã". Competiria a ela, com vistas a resguardar o principal de sua função, a promoção do desenvolvimento (sustentável?), encontrar outro protagonista. E a isso ela estaria se dedicando, com sucesso.

As representações camponesas narrariam, por seu turno, o seguinte: a primeira fase não se caracterizou por ser um preâmbulo para a segunda fase, como 
se quer fazer crer. Ela seria, na realidade, a forma como, deixada à sua própria lógica, a tecnoburocracia do Basa teria absorvido definitivamente as mudanças indicadas pela Constituição. Essa absorção teria um viés regionalista, sim, que, entretanto, simplesmente substituía um grande tomador de recursos públicos (os empresários de outras regiões, os principais beneficiários da era Sudam) por outro grande tomador de recursos (os fazendeiros regionais, fossem eles empresários urbanos latifundizados, fossem eles latifundiários tradicionais buscando modernizar-se $)^{7}$. A segunda fase se explicaria, a sua vez, por um dado exógeno ao campo institucional da intervenção federal na Região: a inusitada capacidade de mobilização reivindicatória demonstrada pelos camponeses no início da década de noventa, inicialmente no Estado do Pará e, depois, por toda Região Norte (Tura, 1996; Rogge, 1998 e Costa, 2000). Esse novo poder teria estabelecido o ideário do desenvolvimento sustentável como orientador de fato das negociações em torno da aplicação dos recursos do FNO - e, assim, teria feito convergir a prescrição constitucional com a prática efetiva do Basa. Debalde, contudo, aduziriam. Pois, mediante as incertezas das novas propostas, os contratos (sempre numa perspectiva da nova economia institucional) se fizeram transferindo ônus de forma desigual aos camponeses.

Com efeito, impuseram-se práticas produtivas temerárias, indicadas por quem chamado a salvaguardar, no papel de autoridade do campo científico-técnico, a eficiência econômica da intervenção. Aqui um fato inesperado: tais autoridades (órgãos de pesquisa agropecuária e assistência técnica) não estavam preparadas para dizer muito sobre o uso sustentável dos recursos naturais na Amazônia, sobre as bases de um novo desenvolvimento na região. Não se fizeram de rogados, todavia. Disseram muito, demais até: rejeitaram os sistemas que funcionavam na prática camponesa, estigmatizados como tradicionais, de baixa rentabilidade; indicaram outros pressupostamente modernos que, todavia não funcionaram ${ }^{8}$. O saldo final foi um aumento sistemático da incerteza de todos os envolvidos e, a isso associada, a formação de custos de transação ex post em montantes consideráveis para o Banco, para sua tecnocracia e, sobretudo, para os camponeses. Diante disso, da parte do Banco observa-se um rápido e fácil retorno à sua clientela "natural" - quando se deveria esperar, ao prevalecer uma auto-atribuída face solidária e desenvolvimentista, uma renovada e mais completa abordagem dos elementos que envolvem o novo tipo de desenvolvimento ${ }^{10}$. Da parte dos camponeses, verifica-se um retorno às formas precárias, porém próprias, com custos de transação zero, de financiamento de suas estratégias de mudança ${ }^{11}$.

Não seria de lamentar, indagariam por fim, o oportunismo ${ }^{12}$ do Basa, que dispondo de recursos a custo de captação zero porque predestinados ao desenvolvimento sustentável - de retorno sabidamente modesto e de longo prazo -, empresta-os a clientes que garantem rápido retorno precisamente por gerirem sistemas produtivos de avaliação duvidosa na sua capacidade econômica de longo prazo e nos aspectos sociais e ecológicos? Não estaria a instituição, em nome da eficiência bancária, negligenciando sua função como agente de desenvolvimento? 


\section{Oportunismo e ambiente institucional}

Há muito mais do que mútuas acusações de oportunismo na experiência acumulada na relação entre os dois mais visíveis protagonistas da inovação institucional representada pelo FNO. Trata-se de uma experiência inédita, de uma vivência institucional complexa que nos fornece elementos para avaliar as dificuldades de institucionalização do ideal da sustentabilidade na Amazônia: o ideal subjacente às atuais disposições de governo, acima enunciadas.

Ela nos sugere duas questões. Estaria na base dessas dificuldades um tradicionalismo dos camponeses, que se constituiria em alguma forma de conservadorismo fundamental responsável pelo baixo nível de realização do potencial que se antevia no $\mathrm{FNO}^{13}$ para induzir processos dinâmicos, com possibilidades de corresponder às expectativas de um novo tipo de desenvolvimento como indica a análise tecnocrática que acima delineamos?

Ou seria, ao contrário, uma aderência primordial entre a tecnoburocracia do Basa e os atores rurais não-camponeses, que inviabilizaria a priori estratégias de desenvolvimento baseadas em estruturas camponesas?

\section{Camponeses, capacidade de mudança e desenvolvimento}

Camponeses têm sido base do desenvolvimento de muitos países e regiões, em situações iniciais não muito diferentes das encontradas em áreas amazônicas (cf., por exemplo, Veiga, 1991 e 1994 e Lopes, 1996).

Nós mesmos temos demonstrado que a disposição a inovar desses atores é variável com uma certa constelação de fatores, mas presente na maior parte do tempo e dos lugares (Costa, 1994, 2000 e 2002), inclusive aqueles considerados tradicionais. Analisamos processos exigentes, de grande envergadura, de mudanças na base produtiva dos camponeses na Amazônia, nos quais, ademais, se demonstra uma inclinação à montagem de sistemas produtivos baseados em diversidade: o que é uma qualidade quando se pretende uma agricultura com máxima esperança de sustentabilidade. Como base na formação de capital social (Putman, 1996 e Coleman, 1990), os camponeses na Amazônia têm mostrado ousadia e capacidade de organização, tanto sindical quanto partidária. A organização sindical e política dos camponeses na Amazônia é já notória, tendo sido o movimento pelas reservas extrativistas e pelo poder político no Acre de ampla repercussão, do mesmo modo que a grande mobilização pela democratização do FNO, primeiramente no Pará e depois por toda a região, eventos avaliados como grandes momentos da historia dessa classe social no País (Tura, 1996; Monteiro, 1996; Aquino, 1998 e Costa, 2000). Por outra parte, é altamente significativo que camponeses considerados os mais tradicionais (no sentido de antigos ribeirinhos) de toda a região, os do Baixo Tocantins, tenham obtido vitórias políticas do porte da assunção da prefeitura de Cametá, por exemplo, vencendo oligarquias de domínio secular (Sousa, 2000). Não é menos importe o que ocorre em Gurupá (uma área tradicional), nem em Nova Ipixuna (uma área de colonização recente), onde os camponeses assumem papéis inequívocos de liderança na con- 
dução de um projeto local de desenvolvimento - assim como na área da Transamazônica. No Sudeste Paraense e no Baixo Amazonas, por sua vez, plantaram-se os protagonistas da produção familiar rural como incontornáveis sujeitos sociais. É notável, também, o grau de organização sindical que se alcançou em Rondônia e, mesmo, no Amazonas.

Não se trata, pois, quando se refere a camponeses na Amazônia, de atores tradicionais no sentido de aversos ou incapazes para mudanças. Se trata, é verdade, de camponeses, como tal, de agentes com atitudes ou, como diria Bourdieu (1994), com habitus próprios. Que não se ajustam a qualquer mudança, ou a mudanças que se pretendem necessárias porque parecem óbvias a outros atores. Que dispõem, sim, de capital humano na forma de saber ancestral, rico, complexo, por uma parte; frágil, por outra parte, diante do avassalador poder da "razão prática" da modernidade capitalista (Habermas, 1995) sequiosa por resultados imediatos - a que serve o capital humano expresso no saber formal amalgamado estritamente pelas necessidades da industrialização. Aliás, a incompatibilidade que existe entre o imediatismo financeiro e o uso prudente dos recursos da natureza específica da Amazônia se expressa com toda a força no antagonismo dessas duas formas de capital humano. Há, contudo, pontos de tangência, áreas de convergência e possibilidades de interação sinérgica entre esses saberes.

Precisamente por isso, o desafio de um novo desenvolvimento de base agrária, na Amazônia, que se caracterize por promover eqüidade e por apresentar maior esperança de sustentabilidade, reside em dar potência às qualidades da produção rural camponesa, do seu conteúdo histórico e social e do habitus de seu protagonista, por uma aproximação construtiva com os acúmulos de conhecimento formal, com o portfolio de saberes aí disponíveis. Esta seria uma construção essencial à institucionalização do ideal de sustentabilidade. Para isso, contudo, seria necessário um ambiente institucional capaz de apreender os requisitos de uma tal tarefa, a saber: valorizar sistemas produtivos baseados em diversidade; formar conhecimentos para a gestão da diversidade; formar conhecimento para transformar a diversidade em base de eficiência econômica (em força produtiva) e de transformar a eficiência econômica em base para a justiça social.

\section{O Basa como parte de um campo institucional, como componente de uma institucionalidade}

Chegamos a um ponto central de toda a questão: a institucionalização do ideal de sustentabilidade implica, a rigor, a reconstrução da institucionalidade que medeia a relação do Estado com as sociedades regionais, isto é, implica a alteração dos nexos objetivos que articulam organizações e visões de mundo, estruturas organizacionais e posturas individuais nessa mediação. As instituições constituem-se em formas concentradas ou difusas, e as sociedades reproduzem-se mantêm-se e evoluem - na interação entre essas duas formas de instituição e seus fundamentos. Na primeira forma, elas são aparatos - privados ou públicos. Como tal, são organizações, estruturas organizacionais, a parte visível de uma institu- 
cionalidade. Na segunda forma, elas manifestam-se nos valores, nos princípios morais e nas percepções de mundo - as quais não são mais que estruturas conceituais que, compartilhadas (cf. Douglas, 1998, p. 18), formam as posturas dos agentes, o poder invisível que faz suas ações convergirem no sentido de reproduzirem estruturas sociais e econômicas, das quais as organizações são parte.

Não faz sentido pensar, assim, uma organização sem o seu campo (Bourdieu, 1994), isto é, sem as outras instituições, tangíveis ou intangíveis, com as quais se relaciona na sua prática cotidiana, estruturando o campo de forças sociais de que faz parte. E, a cada campo corresponde uma "comunidade de pensamento" (Mary Douglas, 1998). Para a compreensão do que se passa com o FNO, não basta, pois, observar o Basa e suas dificuldades de cumprir a Lei no 7.827. Além de espiar para dentro dessa organização (sua definição estatutária), é forçoso observar o que se passa ao lado (com as outras organizações conexas), acima (a visão de mundo que a ela transcende, estabelecendo um "estilo de pensamento" - cf. Mary Douglas - sobre o desenvolvimento regional) e abaixo dela (interesses privado que permeiam suas instâncias).

Olhando para dentro do Basa, perscrutando a sua constituição íntima, deparamo-nos com uma esquizofrenia importante: uma cisão de personalidade entre banco comercial e banco de desenvolvimento. Essa tensão não é trivial, foi bem identificada por Farias (2002) e parece ser a principal responsável por um oportunismo mais propriamente organizacional - a necessidade de uma boa performance comercial, potenciada pela reforma bancária que impõe elevadas exigências de produtividade, levaria o Banco a usar os recursos e a imagem que lhe emprestam o FNO (custo de captação zero, imagem positiva, com selo verde e orientação aos mais fracos) para elevar a lucratividade de suas operações e produtos e, assim procedendo, tenderia a favorecer atividades com rentabilidade de curto prazo, como a pecuária em geral e a pecuária de corte em particular.

Ao lado do Basa, encontramos um conjunto de organizações de Ciência e Tecnologia, para o qual diagnosticamos em outro momento um profundo desenraizamento em relação às necessidades de um desenvolvimento agrário regional em outras bases, mais sustentáveis. Verificamos que, por mecanismos próprios do funcionamento do campo da C\&T, a agropecuária no Brasil e na Amazônia, os esforços de pesquisa têm se feito secundarizando historicamente o tipo de agricultura de que careceria um desenvolvimento sustentável (diversa, complexa, de fundamento perene) - privilegiando, por outra parte, a agricultura homogênea e, particularmente, a pecuária (Costa, 1998). Por seu turno, as organizações que têm por fundamento estatutário a extensão rural, a transmissão dos conhecimentos gerados pela pesquisa agropecuária, além de só disporem daquilo que a pesquisa tem a oferecer, atuam ministrando fórmulas rígidas. Em qualquer dos casos, constata-se um problema fundamental de insuficiência de conhecimento e racionalidade limitada no nível das organizações. 
Acima do Basa e das demais organizações presentes, paira "uma visão de mundo, desenvolvendo um estilo de pensamento" (Douglas, 1998, p. 44) que valoriza os sistemas homogêneos e os procedimentos industrialistas padrão - do que faz parte uma visão segmentada da realidade social. É isso que aprende o estudante de agronomia, é isso que pratica seu professor na instituição de pesquisa, é isso que ele fará como extensionista. O curso de economia ensina a pensar a base produtiva por funções de produção de um único produto, assim procede o analista de crédito no Banco e o conselheiro de mercado na instituição de assessoramento. $\mathrm{O}$ Banco não considera sua a tarefa de pensar a justiça social, muito menos uma justiça social que incorpore as novas gerações. E assim por diante. Assim, a visão de mundo comum que permeia, unindo, as mentes (institucionalizadas), corrobora o desenvolvimento em bases homogêneas e mecânico-químicas, para o qual se espera maior eficiência das grandes estruturas produtivas. Há, aqui, uma dimensão de racionalidade limitada, de insuficiência de conhecimento no plano difuso dos indivíduos, enquanto um problema para a institucionalização, é dizer, para a socialização do ideal de um desenvolvimento sustentável.

Por fim, abaixo das organizações encontram-se os indivíduos com graus de liberdade - tanto em relação à cognição institucionalizada, moralizada, socialmente constrangida, quanto em relação ao poder das organizações, dos aparatos institucionais. Aqui se enquadram tanto as formas mais drásticas como as mais brandas de oportunismo por transgressão individual ou de pequenos grupos, como as muitas formas de desvio de conduta que se fazem em nome do progresso da ciência e de grandes causas. Entre as formas fortes de oportunismo individual encontra-se a corrupção. A partir de um modelo formalmente rigoroso, Lopez (2001) atribui, em evidente redução, à corrupção sozinha a responsabilidade pela manutenção de um status quo dominado pelos grandes proprietários latifundiários em toda a América Latina, em que as possibilidades do desenvolvimento em geral, e de um desenvolvimento de novo tipo, baseado em capital humano e natural, seriam sistematicamente bloqueadas. Mostramos em outro lugar (Tura e Costa, 2000) as oportunidades que a operação do FNO oferece para o fortalecimento desse tipo de obstáculo.

Em resumo: não é o tradicionalismo dos camponeses, mas sim o tradicionalismo do ambiente institucional do qual o FNO é um dado, o principal obstáculo à validação dos elementos do ideário do desenvolvimento sustentável presentes nas disposições constitucionais reguladas pela Lei no ${ }^{0}$ 7.827. Não obstante todas as organizações incluírem em seus folders de apresentação e nos discursos de seus dirigentes a disposição para tal validação, a realidade de suas ações faz-se incorporando estratégias oportunistas e pautadas em conhecimentos insuficientes e/ ou inadequados sobre e para um desenvolvimento sustentável na Amazônia. A institucionalidade é tradicional, portanto, porque assentada sobre uma razão técnica incapaz de lidar conceitual e operacionalmente com o "valor" da 
diversidade para um desenvolvimento duradouro na região, desaparelhada para tratar com os atores capazes de gerir diversidade e com as manifestações e resultados locais dessas capacidades. Ademais, o tradicionalismo tecnocrático tem estatuto político: alimenta-se, é recompensado e arregimenta poder corroborando com o status quo, com visões de mundo e ações que mantêm as formas temerárias e iníquas de desenvolvimento. Em ação, tal tradicionalismo tem criado embaraços de monta para a realização do potencial de mudança que se antevê no estatuto do FNO. A ele deve-se uma longa lista de tropeços da política, alguns dos quais analisamos em Costa e Tura $(2000)^{14}$. Remover suas bases parece ser a tarefa mais urgente.

\section{Um novo desenvolvimento na Amazônia exige uma nova institucionalidade federal na região}

Os desafios acima indicados exigem uma nova institucionalidade federal na Amazônia - uma requalificação do conjunto de aparatos institucionais e normas que expressam o poder federal na região - capaz de uma atuação regeneradora com a finalidade última de minimizar as contradições que, por uma parte, dissociam desenvolvimento econômico e desenvolvimento social e, por outra, tornam o desenvolvimento ameaça a fundamentos naturais únicos e preciosos. $\mathrm{O}$ objetivo deverá ser, pois, o de um progresso social com eqüidade intra- e intergerações, expresso por uma eficiência econômica que tenha as especificidades naturais e culturais da região como aliadas e, por isso, seja sustentável, moderno.

Nesse contexto, o papel do poder federal na região deverá ser o de promover a adequação entre as necessidades inerentes a um desenvolvimento voltado para a emancipação e a inclusão sociais das grandes massas, com os potenciais e limites das bases naturais e culturais presentes na Amazônia. Sua estratégia, a de perseguir um desenvolvimento de base local, dependente e formador de capital humano e social, tecnologicamente baseado no uso denso de conhecimento tácito dos recursos naturais regionais. Um desenvolvimento, assim, irradiador de capacidades difusas, fundamentos de um progresso amplo e socialmente enraizado e, por isso, sustentável, moderno.

A nova institucionalidade, para romper com o tradicionalismo, para atuar acima das disposições oportunistas, para fazer valer os termos do "contrato" constitucional ${ }^{15}$, deverá:

1. Ter a capacidade de conhecer e de arregimentar conhecimento com vistas a oferecer aos processos decisórios públicos e privados, por uma parte, a clara distinção entre desenvolvimento tradicional e desenvolvimento moderno, sustentável; por outra parte, as bases tecnológicas ajustadas ao desenvolvimento moderno na região.

2. Ter a capacidade de mediação das perspectivas de desenvolvimento dos sujeitos sociais no contexto de uma abertura real dos processos decisórios e de uma flexibilização dos mecanismos de intervenção, das quais se espera quebrar as bases dos autoritarismo inerente ao poder tradicional e seu ambiente institucional. 
3. Ter a capacidade de indicar rumos, justificáveis por critérios modernos de desenvolvimento, à ação privada e governos locais na Amazônia.

4. Ter a capacidade de financiamento compatíveis com o projeto de desenvolvimento.

5. Dispor de centro estratégico com porte e configuração organizacional capazes de prover direção e sentido moderno à ação do Estado na Amazônia, pela orientação, acompanhamento e controle do conjunto de seu aparato institucional.

\section{A capacidade de conhecer e de arregimentar conhecimento}

A nova institucionalidade federal na Amazônia deverá basear-se no melhor conhecimento possível sobre a sociedade e a economia amazônicas e sua base natural.

Para isso, seu centro estratégico deverá ser dotado de capacidade própria, que lhes faculte o diálogo crítico e atualizado com as concepções modernas de desenvolvimento que hoje pautam a pesquisa de fronteira das ciências da sociedade e das ciências naturais, onde se destacam as patrocinadas pelas novas teorias institucionais, pelas teorias do desenvolvimento endógeno, pelas teorias evolucionárias das trajetórias tecnológicas, pelos esforços de determinação do peso da cultura e das redes sociais e do papel da especificidade ecológica na capacidade competitiva dos lugares e regiões. Nesse esforço encontrar-se-ão as ferramentas para operar valorizando os arranjos locais, discernindo quanto ao "valor" das suas disponibilidades e carências em termos de capital social, humano e natural.

Necessitará, por outro lado, de capacidade institucional para arregimentar e promover as oportunidades de sistematização do conhecimento já disponível sobre a região, no seu interior e fora dela. Esta deverá ser tarefa rotineira e obsessiva.

A nova institucionalidade federal na região deverá reorientar as pautas das instituições de Ciência \& Tecnologia na região para que, atuando orientadas pelo princípio da diversidade em substituição ao da padronização e da homogeneidade, possam produzir técnicas ajustadas às necessidades regionais.

Por fim, para atuar com discernimento macrosocial a nova institucionalidade federal na Amazônia carecerá também de capacidade para um acompanhamento eficiente do desenvolvimento regional por indicadores que por uma parte contemplem as esferas econômica, social e ambiental e, por outra, permitam observar os níveis micro, meso e macroregional. A montagem de um sistema de informações que culmine numa contabilidade social regional conectada a um sistema de contabilidade ecológica são, para tanto, necessidades imprescindíveis.

\section{Internalizar as perspectivas de desenvolvimento dos sujeitos sociais nos processos decisórios da ação federal}

A nova institucionalidade federal na Amazônia deverá promover a democratização do processo decisório que formata a intervenção desenvolvimentista da esfera federal do Estado na Amazônia. Para tanto, deverá conter mecanismos para uma incorporação dinâmica e qualificada de demandas dos atores sociais coletivos, por meio das representações de grupos relevantes no fundamento pro- 
dutivo (econômico e social) e reprodutivo (econômico, social, político e cultural) do todo social.

Deverá fazer uma incorporação dinâmica das demandas sociais por mecanismos que considerem as dimensões de tempo e lugar do desenvolvimento. $\mathrm{O}$ processo de participação deverá permitir, assim, por um lado, adaptações evolutivas de trajetos de desenvolvimento - para isso terá que ser regular e recorrente, efetivando-se em timing apropriado; por outro lado, dado que essas trajetórias de desenvolvimento são espacialmente referidas, deverá se fazer estreitamente vinculado a lugares e a regiões.

Deverá fazer uma incorporação qualificada, porque derivada de participação que considera o melhor conhecimento prévio disponível do ambiente natural, social e econômico de onde partem as demandas e onde se projetarão os efeitos de seu atendimento, dotando o processo decisório de recursos de aprimoramento e reversibilidade - requisitos fundamentais da sustentabilidade.

\section{Capacidade de indicar rumos}

A nova institucionalidade federal na Amazônia deverá ter capacidade de prover direção, compatível com o sentido estratégico do novo desenvolvimento, à ação de agentes privados e de governos locais na Amazônia. Nesse ponto, tão importante quanto dispor de mecanismos de financiamento é ter capacidade institucional para formular propostas de referência, ex ante e ex post dos momentos-chave dos processos decisórios (antes e depois do ano agrícola, antes e depois das estações de pesca etc., antes e depois dos mandatos executivos etc.). Uma proposta de referência, que pode ser apresentada na forma de um plano de ação, com linhas de investimentos e crédito, além de políticas públicas consistentes, ou simplesmente na forma de relatórios e diagnósticos que apontem consistentemente para tendências e oportunidades, deverá sempre ser um instrumento de convergência entre o que se sabe sobre o lugar e a forma das ações das quais se espera derivar o desenvolvimento moderno e os resultados da incorporação dinâmica e qualificada das perspectivas de desenvolvimento dos sujeitos sociais. Uma vez produzida, esta peça deverá se constituir em parte integrante, em momento particular e ativo, tanto da discussão geral sobre possibilidades e formas de desenvolvimento de novo tipo, quanto da percepção particular de cada sujeito social, de cada ator, de cada agente que participa do processo.

Igualmente importante será a capacidade de colocar as propostas de referência - uma produção coletiva, como se viu, sistematizada contudo no centro estratégico do conjunto institucional - na agenda de todos os agentes, não apenas daqueles que participaram efetivamente, direta ou indiretamente, dos processos de sua formulação. Parte constitutiva dessa capacidade é a difusão dos indicadores, avaliações e estudos intermediários que fundamentaram as propostas de referência. Esse amplo conhecimento é parte do poder orientador das propostas. O papel da comunicação social a ser exercida sobretudo a partir do centro estratégico da institucionalidade é, aqui, central. 


\section{Capacidade de coordenação}

Não raro se sucumbe à tentação de interpretar o desafio da coordenação da ação federal na região como uma obviedade administrativa, como passível de se fazer a partir de delegação formal, de vontade ou de força política. A história dos órgãos de desenvolvimento regional no Brasil e no mundo mostra que não basta a "vontade", a "habilidade" ou, mesmo, a "força" política para que a coordenação aconteça, dado que há fortes fundamentos para a descoordenação. De modo que, o centro estratégico de uma nova institucionalidade federal na Amazônia não deve se fundar sobre as ilusões da coordenação formal, derivada de uma hierarquia normativa, com poucas possibilidades de efetivação. Deve sim, partir do princípio de que a capacidade de prover direção à ação federal na região deverá ser conquistada pela qualidade das suas propostas de referência, pelo efeito crítico dos seus mecanismos de monitoramento e avaliação, pela capacidade desses mecanismos de atingir a menor escala possível, pela criação de oportunidades formais de confrontação entre o dever (das propostas de referência) e o ser (dos indicadores de avaliação das dinâmicas econômicas, sociais e ambientais) e pela ampla divulgação de tudo isso. Sobre este último ponto, convém a consideração do argumento de uma ação descoordenada tem maior chance de ser corrigida se o seu responsável for julgado pela opinião pública. Isso é mais efetivo que "reprimendas", sobretudo se provém de instância institucional que não tem qualquer poder na definição de orçamentos. É que, mediatizado, o "agente descoordenador" deverá pagar com perda de votos e respeitabilidade pública o que tentou ganhar (no geral, também votos) com a transgressão. Ele terá um cálculo de custo-benefício a fazer que provavelmente beneficiará à direção e à coordenação.

\section{Os mecanismos de financiamento}

O processo de construção de um projeto moderno de desenvolvimento exige formas próprias de financiamento, as quais, por suposto, não podem depender de forças ou razões não-modernas, tradicionais, associadas a agentes que não conseguem (por suas posições objetivas na corpo social ou pela história que delimitou suas subjetividades) pensar nem agir modernamente. O Fundo Constitucional de Desenvolvimento do Norte (FNO) tem características que o tornam uma inovação institucional capaz de financiar propósitos modernos de desenvolvimento, na perspectiva aqui colocada. O Fundo de Desenvolvimento da Amazônia (FDA), por seu turno, requer reformulações de grande envergadura.

\section{Um projeto moderno de desenvolvimento não se faz com instituições tradicionais}

Uma intervenção do Estado com o propósito de promover um desenvolvimento de novo tipo na Amazônia é tarefa exigente em conhecimento, em capacidade de formulação estratégica, em capacidade de interação social, em capacidade de formação de opinião, em capacidade de financiamento, em capacidade 
de gestão institucional e em capacidade de direção política. Um requisito primário para tanto é a disposição ao controle social, a adoção da transparência como fundamento institucional a priori.

Ao lado disso, a instituição deve ter porte, capacidade e poder operacional. $\mathrm{O}$ formato da ADA não possibilita o papel de central estratégica na formação e arregimentação dessas capacidades. Olhando apenas pelo perfil organogramático, a estrutura e o porte da "velha" Sudam abrigava os "lugares" institucionais que poderiam arcar com o avultado peso das tarefas, uma vez reformados. Nesse caso, especial esforço de formatação exigirão a criação dos mecanismos de participação sistemática da sociedade civil e das diversas dimensões do Estado, a adequação dos fundos de financiamento, a criação dos mecanismos que permitirão o acompanhamento sistemático das macrovariáveis econômicas, sociais e ecológicas, os mecanismos e procedimentos de elaboração das propostas de referência para a intervenção coordenada com vistas ao desenvolvimento moderno que se pretende.

\section{Das estratégias de intervenção reveladas}

Argumentou-se, até aqui, que um desenvolvimento de novo tipo na Amazônia, um desenvolvimento moderno pois compatível com os ideais democráticos, de justiça social e de equilíbrio ecológico propugnados pelo novo governo, exige um tratamento dos fundamentos da ação federal na região. $\mathrm{O}$ que nos revela o documento de orientações estratégicas do PPA, o PPA-OE, quanto a isso?

\section{O diagnóstico}

O PPA-OE estruturou-se em torno do diagnóstico básico de que:

1. O desenvolvimento econômico está bloqueado pelo estado atual das restrições que produzem vulnerabilidade externa e interna:

a) Vulnerabilidade externa. A baixa capacidade de geração de divisas na balança comercial e de atração de capitais produtivos, face à estagnação da economia e as expectativas desfavoráveis em relação ao seu futuro, tem tornado o País altamente dependente, para fechar sua conta corrente com o resto do mundo, ou de fluxos de capitais com alta volatilidade, ao preço de alta remuneração em moeda doméstica (alta taxa de juros), ou de capitais de empréstimo com alto spread no mercado internacional. Ambas as fontes de captação de recursos externos têm por resultado maiores restrições sobre o investimento produtivo (PPA-OE, I.9, III.2, V.2.56).

b) Vulnerabilidade interna. O investimento privado interno, restringido pela taxa de juros alta, tende a zero nos setores dependentes de demanda interna. A demanda do governo, sobretudo a conformada pelos seus gastos de capital (investimento em infra-estrutura), está estagnada pelas restrições fiscais e orçamentárias infladas pelo efeito da taxa de juros sobre a dívida interna pública. A demanda das famílias, por seu turno, sofre também o efeito deprimente da taxa de juros sobre o consumo. Todavia, a principal restrição aqui se entende ser a estagnação associada à má distribuição da renda, dado que daí resulta o paradoxal e perverso efeito de, nas altas faixas 
de renda, produzir uma saturação de consumo e, nas baixas, uma incapacidade absoluta de consumo (PPA-OE, I.9, I.6).

2. Os surtos de crescimento tenderão a ter fôlego curto se não for possível a transferência de parte dos ganhos de produtividade em capacidade de consumo das massas trabalhadoras.

3. O controle da inflação (que pressupõe rigor fiscal e orçamentário do governo) e a elevação do saldo em conta correntes são pressupostos de um novo surto de investimento e consumo porque pressupostos para a redução da taxa de juros. A duração desse surto, entretanto, que possa caracterizá-lo como ciclo de desenvolvimento, requer superar fundamentos estruturais: alterar os fundamentos da geração e distribuição da riqueza.

\section{A estratégia nacional para o desenvolvimento}

A estratégia nacional, como indicado, prevê dois movimentos, em dois tempos. O primeiro movimento, o que deverá produzir a redução na taxa de juros e com isso elevar a capacidade de investimento interno, das empresas e do governo, deve se passar no curto prazo; o segundo movimento, aquele que deverá produzir capacidade sustentável de consumo das famílias e manter alta a do governo, requererá tempo mais largo, não obstante uma atuação emergencial imediata (Programa Fome Zero etc.). O primeiro movimento é pressuposto para o segundo e, por suposto, tem sobre ele total precedência.

Um implicação disso é que se tornam temas de máxima prioridade, no plano econômico, a elevação do saldo da balança comercial e, no plano institucional, a condução das reformas que dêem imediata capacidade de investimento ao Estado. No primeiro caso, levando a tratamento com grande deferência estratégica os setores, segmentos e ramos produtivos que apresentem alto grau de internalização de suas cadeias produtivas e, assim, apresentem coeficientes de importação baixos: uma forte expansão produtiva para exportar não implica, em tal contexto, crescimento proporcional das importações, permitindo um resultado líquido maior nas contas correntes externas. No segundo caso, tornando objeto de grande deferência estratégica todas as forças políticas capazes de bloquear as reformas tributárias e previdenciária - as que mais diretamente afetam o balanço fiscal e orçamentário do governo federal.

\section{Para além do lugar da região na estratégia nacional - pela internalização na nação de estratégias regionais pactuadas}

Na estratégia acima, a principal referência de competitividade é o mercado internacional de bens com baixo coeficiente de importação. O tempo da estratégia competitiva, o curto prazo, o agora. Elevar a integração competitiva das regiões significa aumentar o poder aquisitivo das regiões e setores com capacidade competitiva internacional para que adquira os bens produzidos nas regiões e setores essencialmente voltados para o mercado interno. A dimensão infra-estrutural visível é a ajustada a tal integração, dominantemente capital físico: estradas, hidrovias e portos. 
Uma implicação imediata de tais lineamentos estratégicos sobre a questão regional amazônica é a de que tais prioridades convergem com a produção de gado, soja e madeira. Tais produções podem ser aumentadas em curtíssimo prazo, seu coeficiente de importações é baixíssimo, a competitividade internacional pouco contestável. O que poderia revalorizar o projeto latifundiário-monocultural de que acima tratamos, fazê-lo ganhar novos níveis na já presente trajetória ascendente na absorção dos recursos de desenvolvimento regional. Por outro lado, aguça-se, a partir daí, uma tensão fundamental entre as necessidades emergenciais do projeto nacional e um tipo de desenvolvimento, como o familiar-policultural, que, não obstante poder produzir capacidades competitivas novas e mais sustentáveis, posto que baseada em conbecimento e capacidade organizacional, apresenta o problema de requerer mais tempo, de precisar de horizontes de meio e longo prazos.

Acirrar as assimetrias entre os dois projetos é aprofundar os conflitos daí derivados. Precisamente aqui se inscreve o principal componente da questão fundiária. Mas tal questão insere-se numa questão agrária mais ampla, derivada do fato de que a evolução de um projeto não é neutra em relação aos fundamentos do outro: da mesma maneira como a terra que se precisará para plantar soja deixará de existir para a agricultura diversa, o pesquisador que se voltar para um projeto faltará ao outro, a infra-estrutura que se prioriza para este não é a que seria premente para aquele etc. Na verdade, a evolução de um projeto se faz negando fundamentos para o outro projeto em movimentos contraditórios: um projeto se nutre do que seria essencial para a existência do outro. Debalde, nesse contexto a pretensão de PPA-OE de compensar as forças colossais provenientes da esfera econômica, com as quais corroborarão os fortes mecanismos da política econômica (cf. PPA-OE, V.2.56 e 57), por políticas compensatórias na esfera social, com as quais corroborarão os frágeis mecanismos da política social (PPAOE, III.3).

Poder-se-ia argumentar, neste ponto, com os tempos estratégicos do projeto nacional: as forças do projeto latifundiário-monocultural que no curto prazo atuariam para corroborar o projeto nacional seriam substituídas pelas forças do projeto familiar-policultural, que no longo prazo consolidariam um projeto moderno de desenvolvimento sustentável. É possível... Tal ideal, contudo, requer a formação de uma consistente institucionalidade, nos moldes exigentes que acima expusemos: baseada em flexibilidade e abertura do processo decisório, em ampliação do conhecimento e em coordenação operacional. Esforço nessa direção, diga-se, está sendo feito, exigindo dos atuais gestores federais na Amazônia um grande discernimento estratégico e capacidade política para formatação, compatível com os desafios, dos quadros dirigentes e das próprias normas e estatutos vigentes. Nessa direção caminham a proposta de criação de uma nova Sudam e, já nos precários marcos institucionais da ADA, o estabelecimento de uma série de mecanismos para abrir o processo decisório tanto das grandes questões estratégicas da região, como da operação de tais estratégias em recortes estruturais e 
espaciais bem precisos; busca-se modernizá-lo no sentido de torná-lo um espaço de governança no estilo state in the society. Com esse propósito vem-se criando desde um Fórum de Gestores Federais na Amazônia, em fase de institucionalização, até comitês gestores de Arranjos Produtivos Locais, a exemplo do que já opera para a fruticultura e produção e polpa de frutas do Nordeste Paraense.

Há dificuldades, contudo, dado que as necessidades de alianças nacionais para as reformas prioritárias reduzem a capacidade política de formatação da institucionalidade necessária para um desenvolvimento de outro tipo. Esse efeito é tanto mais forte e profundo, quanto mais o projeto nacional requeira a cooptação das agremiações políticas com grande presença das oligarquias regionais. Uma vez presentes na institucionalidade federal na região, tais forças tenderão a atuar na confirmação do projeto latifúndiário-monocultural.

Notas

1 Foi elaborado por comissão interministerial do Ministério da Integração e do Ministério do Meio Ambiente um Plano Amazônia Sustentável, o qual ainda não foi dado a conhecer (cf. Santana, 2004).

2 Instituições, segundo Douglas North, "são o filtro entre os indivíduos e o estoque de capital [a soma das disponibilidades em capital físico, capital humano e capital natural] e entre este e a produção e distribuição de bens, serviços e renda" (North, 1981, pp. 4-5 e 201).

3 Assim criado, o Fundo Constitucional de Desenvolvimento do Norte (FNO) é parte do que North entenderia ser a "mais fundamental restrição organizacional do sistema econômico": as regras constitucionais, no que se refere ao seu objetivo de "especificar um padrão de distribuição de riqueza e renda" (North, 1981, p. 205).

4 Entendendo instituição como conjunto de regras, procedimentos de controle e normas de coerção do comportamento individual com vistas à maximização de objetivos de atores coletivos (pequenos ou grandes grupos - comunidades ou classes) ou particulares (indivíduos, agentes), a Nova Economia Institucional enunciaria que os contratos produzidos em torno do FNO (da sociedade e Estado brasileiros com o Basa e deste com os diversos grupos e agentes que acessam ou medeiam o acesso ao crédito) deveriam objetivar a maximização de uma "utilidade" especial, a saber: maior eqüidade entre as regiões pelo desenvolvimento mais rápido da região Norte comparativamente ao resto do País. Nesse sentido, tais contratos deveriam produzir convergência entre as decisões dos atores coletivos que se fariam obedecendo a resultados de cálculos de custo/benefício social (a percepção coletiva de que abrir mão dos recursos do FNO foi mais que compensado pelo desenvolvimento da região) e aquelas decisões dos agentes, para as quais prevaleceriam cálculos de custo/benefício privado, cujos melhores resultados dependeriam crucialmente da redução de custos, tanto daqueles associados à produção, quanto dos outros originados nas transações (Williamson, 1985, pp. 15-19).

5 Farias (2002) reproduz algumas falas com esse conteúdo. 
6 Utiliza-se, aqui, a noção de oportunismo validade pela nova economia institucional: é oportunista o comportamento resultante da disposição pressupostamente latente nos agentes de não cumprir um contrato se o custo que se presume derivar da retaliação for menor que o ganho com a ruptura do acordo. Essa disposição aumenta quando há assimetria de conhecimento e poder na formulação do contrato, no acompanhamento e no controle do processo, do qual emergirá a utilidade contratada (Williamson, 1985, p. 80).

7 Nesse sentido, este seria mais um movimento no processo que chamei em outro lugar (1992) de "reoligarquização" do agrário regional.

8 Para uma análise detalhada ver Costa, 2000 e Solyno, 2000.

9 Além das séries apresentadas, a rapidez dos processos é corroborada no caso particular do Estado do Pará e, mais acentuadamente ainda, no caso da Mesorregião Sudeste Paraense - uma área de intenso movimento de fronteira protagonizado por uma pecuária extensiva, cujo avanço tem produzido fortes tensões sociais. No Pará, a pecuária de corte, que representava 19\% dos financiamentos em 1996, passa a representar 30\% no ano de 2000; as permanentes caem no mesmo período de $40 \%$ para a $27 \%$. No Sudeste Paraense, por sua vez, a pecuária de corte passou de $26 \%$ para $39 \%$ e as permanentes de $20 \%$ para $13 \%$.

10 Que envolveria uma necessária ênfase na agroindustrialização, como complementação à fase anterior. Não é o que acontece, como frisa Santana: “o desequilíbrio em relação à agroindústria é injustificável ou até mesmo imperdoável, uma vez que [...] este é um segmento que pode, em curto ou médio prazo, viabilizar a formação de agrupamentos produtivos sinérgicos, nos eixos de desenvolvimento traçados no Programa Avança Brasil para a Amazônia” (Santana, 2000, p. 72). Ver também sobre isso Costa et alii, 2004.

11 São ilustrativos, sobre este'último ponto, os resultados que obtivemos em pesquisa de campo em parceria com o Lasat, com 310 estabelecimentos familiares na região polarizada por Marabá: o investimento feito em culturas permanentes por estes estabelecimentos cresceu extraordinariamente, saindo de um índice cem em 1990 para 128 em 1995 e para 220 em 2000. Dessas inversões, contudo, apenas 7\% foram financiados pelo FNO.

12 As possibilidades de comportamento oportunista aumentam quando se verifica aquilo que a nova economia institucional conhece como problema de mensuração: as dificuldades postas pela racionalidade limitada (ou, quando se trata de organizações, pelo conhecimento institucionalizado insuficiente) para a formulação perfeita do contrato e para o acompanhamento e controle do processo, do qual emergirá a utilidade contratada (Williamson, 1985, p. 80). A aplicação de recursos sociais com as características do FNO tem, de início, um problema de mensuração na medida em que a "utilidade desenvolvimento", seu objeto contratual, comporta diversos significados, gerando, tal fato, “ambigüidades de atributos e performance” (Williamson, 1985, p. 2) associados à sua consecução.

$13 \mathrm{O}$ potencial do FNO derivaria de suas características formais inovadoras, já enunciadas. Em conjunto elas a) oferecem a possibilidade de gestão flexível e compartilhada dos recursos do Fundo e, por isso, b) permitem abrigar agendas locais e c) ajustar com relativa rapidez a processos específicos, para potenciá-los ou contrariá-los. 
$14 \mathrm{O}$ seguintes pontos foram os mais destacados: tutelamento conservador das inovações; financiamento de sistemas dominantemente homogêneos ou com baixo grau de complexidade e, por isso, com elevado grau de risco; desconsideração do potencial de capital humano real disponível (preexistente); baixa influência na formação de capital humano "novo" (capaz de lidar com os pressupostos de um desenvolvimento endógeno na Amazônia); desconsideração do potencial de valorização do ecossistema originário; e a produção desnecessária de inadimplência (que chamamos de técnica porque forcada pelos pacotes de investimento) e risco social (Tura e Costa, 2000).

15 Douglas North entende que as normas constitucionais são a "mais fundamental restrição organizacional do sistema econômico", cujo objetivo seria o de "especificar um padrão de distribuição de riqueza e renda" (North, 1981, p. 205). As regras dos Fundos Constitucionais podem ser compreendidas por esse prima.

\section{Bibliografia}

AQUINO, O. G. de. Do cooperativismo tradicional ao alternativo: a trajetória do movimento social rumo às novas formas de integração camponesa no estado do Pará. Dissertação de mestrado, Belém, UFPA-Plades/ Naea, 1998.

BOURDIEU, P. Razões práticas: sobre a teoria da ação. Campinas, Papirus, 1996.

Questões de sociologia. São Paulo, Marco Zero, 1983.

BRASIL. Ministério da Integração Nacional. www. integracao.gov.br/pdf/fundos/signovembro_2001.pdf, 2002.

BRITO, D. C. A modernização da superfície: estado e desenvolvimento na Amazônia. Belém, Naea, 2001.

COLEMAN, J. Foundations of Social Theory. Cambridge, Mass. Harvard University, 1990.

COSTA, F. de A. Ecologismo e questão agrária na Amazônia. Belém, Sepeq/ Naea, 1992.

Ciência, tecnologia e sociedade na Amazônia. Belém, Sejup, 1998.

Formação agropecuária da Amazônia: os desafios do desenvolvimento sustentável. Belém, Naea, 2000.

. "As ciências, o uso dos recursos naturais na Amazônia e a noção de desenvolvimento sustentável: por uma interdisciplinaridade ampla”. Em VIEIRA, I.; SILVA, J. M. C.; OREN, D. C. e D’INCAO, M. A. Diversidade biológica e natural da Amazốnia. Belém, MPEG, 2001.

COSTA, F. A. "Políticas públicas e dinâmica agrária na Amazônia: dos incentivos fiscais ao FNO”. Em TURA, L. e COSTA, F. A. Campesinato e Estado na Amazônia. Brasília, Brasília Jurídica-Fase, 2000.

COSTA, F. A.; ANDRADE, W. e FIOCK, F. “A produção de polpa de frutas no Nordeste Paraense: um arranjo produtivo emergente". Relatório de Pesquisa apresentado à RedeSiste, UFRJ, maio 2004.

DOUGLAS, M. Como as instituições pensam. São Paulo, Edusp, 1998. 
FARIAS, A. L. A. O crédito no Pará (1995-2000): Uma abordagem sociológica do financiamento do desenvolvimento regional. Dissertação de mestrado, Belém, Plades/ Naea, 2002.

HABERMAS, J. Theorie des kommunikativen Handelns. Frankfurt am Main, Suhrkamp, 1995.

KRUGMAN, P. Development, Geography, and Economic Theory. Cambridge, The MIT Press, 1995.

. Geography and Trade. Cambridge, The MIT Press, 1991.

. The Self-Organizing Economy. Oxford, Blackwell, 1998.

LOPES, M. de R. Agricultura politica: história dos grupos de interesse na agricultura. Brasília, Embrapa, SPI, 1996.

LOPES, R. "Growth, Poverty and Asset Allocation: The Role of the State". ZEF-Working Papers on Developmente Policy, n. 35, Center for Development Research, Bonn, mar. 2001.

MONTEIRO, R. Informação e redes de interação no novo ciclo de mobilizações dos pequenos agricultores da Transamazonica. Dissertação de mestrado, Belém, Plades/ Naea, 1996.

NORTH, D. Structure and Change in Economic History. New York/ London, W. W. Norton and Company, 1981.

PORTER, M. E. A vantagem competitiva das nações. Rio de Janeiro, Campus, 1989.

PUTMAN, R. e HELLIWELL, J. "Economic Growth and Social Capital in Italy". Eastern Economic Journal, vol. 21, n. 3, 1995.

PUTNAM, R. Comunidade e democracia: a experiência da Itália moderna. Rio de Janeiro, FGV, 1996.

ROGGE, J. Parás Kleinbauernbewegung: Die Kleinbauerbewegung im Nordostens Paras (Brasilien). Mettigen, Brasilienkunde-Verlag, 1998.

TURA, L. "Notas introdutórias sobre os Fundos Constitucionais de Financiamento e sua configuração na região Norte". Em TURA, L. e COSTA, F. A. Campesinato e Estado na Amazônia. Brasília, Brasília Jurídica-Fase, 2000, pp. 29-46.

SOLYNO, S. A. “Capacidade de pagamento e viabilidade técnica do FNO-Especial para o desenvolvimento da produção familiar rural no estado do Pará”. Em TURA, L. e COSTA, F. A. Campesinato e Estado na Amazônia. Brasília, Brasília Jurídica-Fase, 2000, pp. 177-224.

. Gritos do campo: reconbecimento político e exercícios de cidadania no Pará. Dissertação de mestrado, Rio de Janeiro, IFCS-UFRJ, 1996.

TURA, L. R. e COSTA, F. A. Campesinato e Estado na Amazônia. Brasília, Brasília Jurídica-Fase, 2000.

SANTANA, L. "Política para Amazônia ainda não saiu do papel”. O Estado de S.Paulo, $2 / 5 / 2004$, p. A12.

SANTANA, A. C. Impactos socioeconomicos do Fundo Constitucional de Financiamento do Norte (FNO) nas atividades produtivas da Região Norte: análise de insumo-produto. Mimeo., 2002. 
SOUSA, R. V. Reprodução camponesa, crédito e organização coletiva. Dissertação de mestrado, Belém, Plades/Naea, 2000.

WILLIAMSON, O. The Economic Institutions of Capitalism. New York, Free Press, 1985.

VEIGA, J. E. O desenvolvimento agrícola: uma visão histórica. São Paulo, Edusp/ Hucitec, 1991.

. Metamorfoses da politica agrícola dos Estados Unidos. São Paulo, Annablume/ Fapesp, 1994.

VELHO, O. G. Capitalismo autoritário e campesinato. São Paulo/ Rio de Janeiro, Difel, 1976.

RESUMO - OS ENUNCIADOS estratégicos do Governo do PT iniciado em 2003 reafirmam anecessidade de desenvolvimento com base na expansão do mercado interno, modelo que, em suas linhas gerais, vem orientando discussões internas e atuações políticas do PT há muito tempo. Colocam, porém, duas novidades de grande significado: a elevação da estabilidade macroeconômica à condição de pressuposto e da sustentabilidade ambiental à condição de atributo do desenvolvimento. A combinação desses três elementos produz grandes desafios para o Governo Federal, podendo gerar inconsistências entre as soluções que se formam pensando o País e as condições particulares da questão amazônica. Urge descortinar tais inconsistências e indicar caminhos de sua superação.

ABSTRACT - THE STRATEGIC statements of the PT Government that started in early 2003 reaffirm the need for the country to develop based on the expansion of the domestic market, model that, in your general lines, is guiding internal discussions and political performances of the PT since long. They place, however, two innovations of great meaning: the guarantee of a macroeconomic stability as presupposition of the development and the environmental sustainability as its attribute. The combination of those three elements produces great challenges for the Federal Government and thus could generate inconsistencies among the solutions thinking Brazil as a whole and the peculiar conditions of the Amazon subject. It urges to explain such inconsistencies and to indicate modes to overcome them.

Palavras-chave: Amazônia, Questão Agrária, Políticas Públicas.

Keywords: Amazon, Agrarian Issue, Public Policies.

Francisco de Assis Costa é doutor em Economia pela Universidade Livre de Berlim, professor e pesquisador do Naea/UFPA. Coordenador geral de Planejamento e Gestão Estratégica da Agência de Desenvolvimento da Amazônia (ADA).

Texto recebido em 28 de dezembro de 2004 e aceito para publicação em 26 de janeiro de 2005. 